\title{
Characterizing Observed Midtopped Cloud Regimes Associated with Southern Ocean Shortwave Radiation Biases
}

\author{
SHANNON MASON AND CHRISTIAN JAKOB \\ Monash Weather and Climate, Monash University, Melbourne, Victoria, Australia
}

ALAIN PROTAT

Centre for Australian Weather and Climate Research, Bureau of Meteorology, Melbourne, Victoria, Australia

JULIEN DELANOË

Laboratoire Atmosphéres, Milieux, Observations Spatiales, UVSQ/IPSL/CNRS, Paris, France

(Manuscript received 21 February 2014, in final form 22 April 2014)

\begin{abstract}
Clouds strongly affect the absorption and reflection of shortwave and longwave radiation in the atmosphere. A key bias in climate models is related to excess absorbed shortwave radiation in the high-latitude Southern Ocean. Model evaluation studies attribute these biases in part to midtopped clouds, and observations confirm significant midtopped clouds in the zone of interest. However, it is not yet clear what cloud properties can be attributed to the deficit in modeled clouds. Present approaches using observed cloud regimes do not sufficiently differentiate between potentially distinct types of midtopped clouds and their meteorological contexts.

This study presents a refined set of midtopped cloud subregimes for the high-latitude Southern Ocean, which are distinct in their dynamical and thermodynamic background states. Active satellite observations from CloudSat and Cloud-Aerosol Lidar and Infrared Pathfinder Satellite Observations (CALIPSO) are used to study the macrophysical structure and microphysical properties of the new cloud regimes. The subgrid-scale variability of cloud structure and microphysics is quantified within the cloud regimes by identifying representative physical cloud profiles at high resolution from the radar-lidar (DARDAR) cloud classification mask.

The midtopped cloud subregimes distinguish between stratiform clouds under a high inversion and moderate subsidence; an optically thin cold-air advection cloud regime occurring under weak subsidence and including altostratus over low clouds; optically thick clouds with frequent deep structures under weak ascent and warm midlevel anomalies; and a midlevel convective cloud regime associated with strong ascent and warm advection. The new midtopped cloud regimes for the high-latitude Southern Ocean will provide a refined tool for model evaluation and the attribution of shortwave radiation biases to distinct cloud processes and properties.
\end{abstract}

\section{Introduction}

Clouds regulate the atmospheric radiation budget, and are a key mechanism in the hydrological cycle and global atmospheric circulation. The representation of cloud processes, properties and radiative effects-now and in a changing climate-are therefore both a priority and an ongoing challenge for model development.

Corresponding author address: Shannon Mason, Monash Weather and Climate, Monash University, Melbourne VIC 3800, Australia.

E-mail: shannon.mason@monash.edu
One of the most significant cloud errors in global climate models is the poor representation of cloudiness over the high-latitude Southern Ocean $\left(50^{\circ}-65^{\circ} \mathrm{S}\right)$ and a corresponding positive bias in shortwave (SW) radiation absorbed at the top of the atmosphere and absorbed at the surface during the austral summer (Trenberth and Fasullo 2010; Li et al. 2013). The excess downwelling SW radiation in the models is associated with warm sea surface temperature biases that have also been linked to errors in the representation of the Southern Hemisphere circulation, including the position of the midlatitude jet (Ceppi et al. 2013), the strength of meridional energy transport (Donohoe and Battisti 2012), and the double 


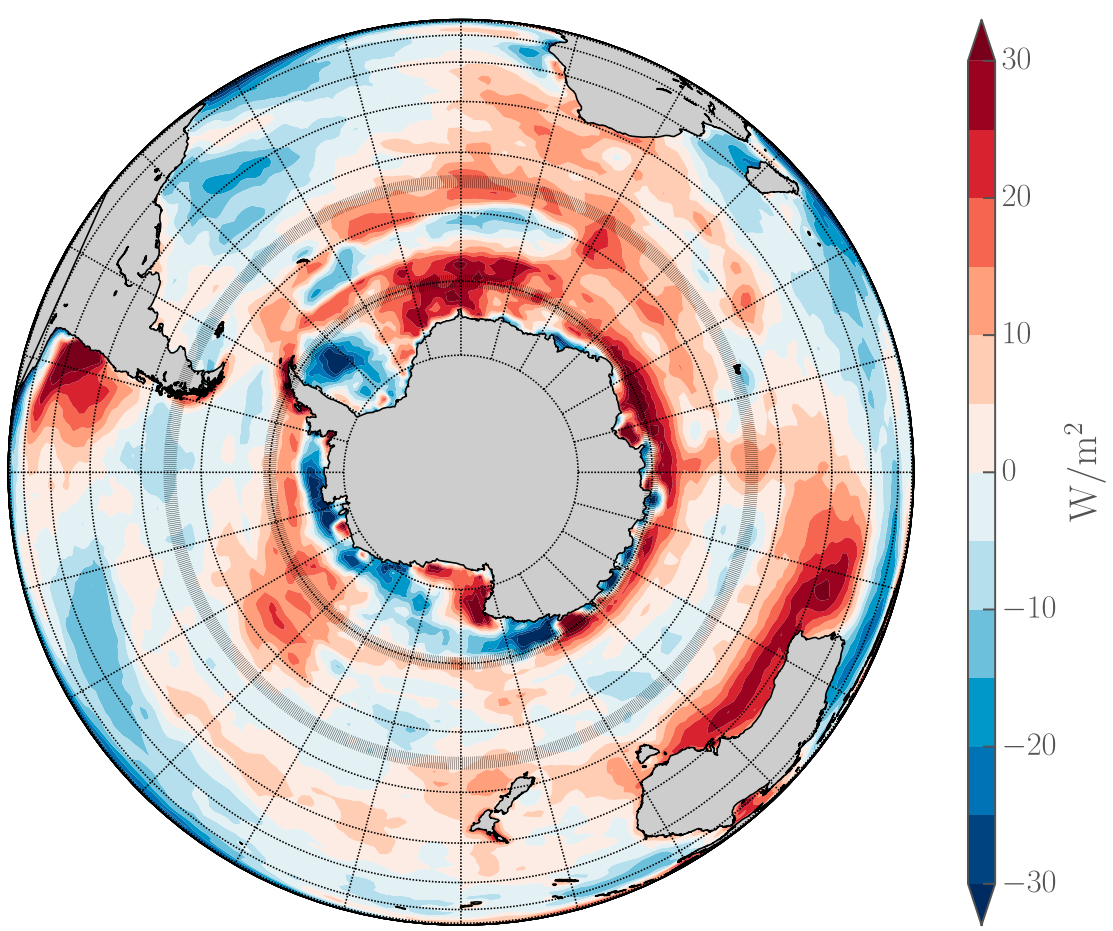

FIG. 1. CMIP5 multimodel mean of $\mathrm{CRE}_{\mathrm{Sw}}$ bias relative to Clouds and the Earth's Radiant Energy System (CERES) Energy Balanced and Filled (EBAF; Loeb et al. 2009) observations over the Southern Ocean for the austral summer (DJF). The zone of interest for the strongest zonal bias $\left(50^{\circ}-65^{\circ} \mathrm{S}\right)$ is indicated with thick black lines.

intertropical convergence zone problem (Hwang and Frierson 2013).

The multimodel-mean bias of SW cloud radiative effect $\left(\mathrm{CRE}_{\mathrm{SW}}\right)$ for phase 5 of the Coupled Model Intercomparison Project (CMIP5; Taylor et al. 2012) is shown over the Southern Ocean for the austral summer [December-February (DJF)] in Fig. 1. The zonal-mean bias (not shown) is largest poleward of $50^{\circ} \mathrm{S}$ and reaches a maximum of $10-15 \mathrm{~W} \mathrm{~m}^{-2}$ in the zone $60^{\circ}-65^{\circ} \mathrm{S}$.

The causes of the Southern Ocean cloud errors remain poorly understood and may not be the same in every model. Despite some decades of satellite data, research has been hindered by an historical and geographical dearth of observations from Earth's most remote ocean, especially at higher latitudes: the Southern Ocean Cloud Experiments (SOCEX I and II; Boers et al. 1996, 1998) were conducted in the 1990s with instrumented aircraft over a limited area off the coast of Tasmania, while some surface observations from the research vessel Aurora Australis are available at high latitudes in the Eastern Antarctic (Fitzpatrick and Warren 2007). In the last decade, active satellite observations have presented a new opportunity to improve our understanding of Southern Ocean clouds; recent studies have used radar and lidar profiles to produce detailed climatologies and vertical profiles of Southern Ocean clouds in terms of cloud microphysics and macrophysics (Mace 2010; Huang et al. 2012a,b; Verlinden et al. 2011).

A useful approach to identifying and distinguishing between cloud processes or properties is to group selfsimilar cloud scenes based on passive satellite observations of cloud-top properties (Jakob et al. 2005; Rossow et al. 2005). This method has been used in the midlatitudes to show that cloud regimes make useful distinctions between meteorological conditions (e.g., Gordon and Norris 2010; Oreopoulos and Rossow 2011). Haynes et al. (2011) identified eight cloud regimes in the Southern Ocean band $30^{\circ}-65^{\circ} \mathrm{S}$ and described some aspects of their meteorological contexts, cloud macrophysics and microphysics, and radiative properties; two cloud regimes were found to have the greatest effect on the overall SW radiation budget in the area: an optically thick midtopped cloud regime and a very frequent low cloud regime.

A similar method based on mean cloud-top properties is frequently used for model evaluation (see Williams and Webb 2009). Historically, climate models have tended to overestimate frontal cloud and optically thick low cloud while underrepresenting optically thin low cloud (e.g., trade cumulus) and midtopped clouds (Webb et al. 2001; Zhang 2005; Williams and Tselioudis 2007). In 
the Southern Ocean, some recent studies related the SW radiation biases in the models to the frequency of occurrence of a single midtopped cloud regime, which has been associated with both the cold-air part of extratropical cyclones and regions ahead of transient ridges in studies using composite cyclones (Bodas-Salcedo et al. 2012; Williams et al. 2013). Bodas-Salcedo et al. (2014) showed that the observed macrophysical structures within the single midtopped cloud regime are highly variable: low clouds dominate the cloud regime with and without accompanying cloud at middle levels, while midlevel cloud in isolation is very rare.

In the study of Haynes et al. (2011), two midtopped cloud regimes were identified in the Southern Ocean, which were associated with a broad range of meteorological conditions. This suggests that cloud scenes categorized as midtopped by passive satellite observations may have very different physical properties and presumably are associated with different cloud processes. If true, this would make the use of a single regime in model evaluation problematic, as it cannot distinguish between different important meteorological contexts, the very paradigm underpinning the use of cloud regimes in model evaluation.

The main purpose of this study is to investigate the degree to which the cloud properties and meteorological contexts of the midlevel cloud regimes identified in Haynes et al. (2011) are homogeneous. We demonstrate that the existing midtopped cloud regimes do not offer a sufficient representation of the cloud processes and physical properties encountered in the Southern Ocean region. We identify four midtopped cloud subregimes for the high-latitude Southern Ocean based on cloudtop observations and also consider two low cloud regimes that are frequent in the area of interest. To better characterize the clouds associated with the SW radiation bias we present their meteorological contexts, their mean macrophysical and microphysical properties, and demonstrate an approach to quantifying the subgridscale variability of cloud structure and phase.

\section{Data and methodology}

Southern Ocean cloud regimes have been identified based on passive cloud-top observations from the International Satellite Cloud Climatology Project (ISCCP; Rossow and Schiffer 1999) D1 data, which consist of day-lit 3-h joint histograms of cloud-top pressure (CTP) and optical thickness $(\tau)$ over a $280 \mathrm{~km} \times 280 \mathrm{~km}$ equalarea grid for the period 1983-2008. ISCCP D1 data have been interpolated on to a regular $2.5^{\circ}$ grid using a nearestneighbor interpolation scheme, and the cloud regimes are defined on this grid. Cloud regimes are identified by using a $k$-means clustering algorithm (Anderberg 1973) to iteratively group self-similar clouds according to the Euclidean distances between their $\mathrm{CTP}-\tau$ joint histograms. Eight cloud regimes for the Southern Ocean (defined as $30^{\circ}-65^{\circ} \mathrm{S}$ ) have been identified from daily daytime means of ISCCP D1 data as described in Haynes et al. (2011); using daily means instead of 3-h data was found to have negligible effect on the results of the clustering of cloud regimes or on the subsequent analysis of concurrent meteorology from reanalysis data. We note that these cloud regimes are nearly identical to the weather states identified using the same methodology in Oreopoulos and Rossow (2011) for the slightly different region $35^{\circ}-$ $65^{\circ} \mathrm{S}$; however, the cloud regimes and nomenclature from the former study are used here.

The dynamical and thermodynamical contexts of the cloud regimes are characterized using meteorological data from the Interim European Centre for MediumRange Weather Forecasting (ECMWF) Re-Analysis (ERA-Interim; Dee et al. 2011), which provides 6-h fields at $1.5^{\circ}$ resolution and 37 pressure levels for the period 1979-2011. For this study the vertical pressure velocity $(\omega)$ and relative humidity $(R)$ fields are used directly, while temperature and the horizontal wind components are used to calculate potential temperature $(\theta)$ and temperature advection $(-u \cdot \nabla T)$. Daily averages of all ERA-Interim fields are linearly interpolated to the same $2.5^{\circ}$ grid as the ISCCP cloud regimes. For $R$ and $\theta$ profiles, local anomalies are derived by subtracting the contemporary monthly mean from the daily average at each grid point to remove strong regional or zonal variations in the mean fields (Gordon et al. 2005; Gordon and Norris 2010).

The macrophysical structures and microphysical properties of the cloud regimes are characterized using active satellite observations from the radar-lidar (DARDAR; Delanoë and Hogan 2010) classification, a merged data product derived from two instruments closely following one another in the A-Train satellite constellation: the Cloud Profiling Radar (CPR) aboard CloudSat (Stephens et al. 2008) and the Cloud-Aerosol Lidar with Orthogonal Polarization (CALIOP) aboard Cloud-Aerosol Lidar and Infrared Pathfinder Satellite Observations (CALIPSO; Winker et al. 2007). Cloud masks from CPR and CALIOP, as well as temperature from the ECMWF reanalysis, are interpolated on to a common grid with 60-m vertical and 1-km horizontal resolution. Radar is sensitive to ice particles and lidar to small liquid water droplets, so collocated radar and lidar masks can be used to estimate the cloud thermodynamic phase: where the radar identifies cloud but lidar does not, DARDAR assigns the cloud pixel as ice (ICE); where lidar detects liquid water but radar 
backscatter does not suggest ice particles, the temperature field is used to distinguish between warm liquid water (WLW) and supercooled liquid water (SLW); and where both radar and lidar detect cloud, mixedphase cloud (ICE + SLW) is identified. Warm precipitation (RAIN) is also included for completeness, since DARDAR does not distinguish between cloud ice and precipitating ice. The strong interaction of lidar with liquid water droplets leads to significant attenuation through these clouds; where lidar is extinguished but radar suggests cloud, DARDAR returns the "unknown" classification. For this reason we expect the DARDAR classification mask to underestimate the frequency of occurrence of the known cloud phase categories in the lowest part of the profile, specifically below $1.5 \mathrm{~km}$ and especially below thick cloud, below liquid water, or in layered scenes (Protat et al. 2014). Hence, when identifying cloud frequency of occurrence from the DARDAR cloud classification mask we make a cautious upper estimate of cloud amount by including the unknown category, which is likely to represent cloud where the lidar is extinguished. To indicate these uncertainties, the lower $1.5 \mathrm{~km}$ is stippled in all depictions of vertical profiles using DARDAR data.

\section{The key midlevel cloud regimes}

A cloud regime analysis supposes that each cloud regime is associated with a group of morphologically similar clouds and, to some degree, that the members of each cloud regime have a common meteorological context. They are sometimes called weather states for this reason (e.g., Rossow et al. 2005). This assumption can be evaluated by investigating if the regimes are associated with distinct and consistent atmospheric states. Compositing a set of dynamical and thermodynamical variables by cloud regime, we should be able to identify meteorological conditions that can be physically related to the cloud morphologies upon which the cloud regimes are determined.

\section{a. Selected Southern Ocean cloud regimes}

We have taken as a starting point the eight cloud regimes identified in Haynes et al. (2011) for the Southern Ocean band $30^{\circ}-65^{\circ} \mathrm{S}$. The relative frequency of occurrence of these cloud regimes within the zone of interest $50^{\circ}-65^{\circ} \mathrm{S}$ during DJF are shown in Table 1; we select for this study the low-topped and midtopped cloud regimes with the highest relative frequencies of occurrence in the region and period of interest: S1, S3, S4, and S5. Several of these cloud regimes are significant contributors to the overall CRE $\mathrm{CW}_{\mathrm{Sw}}$ (Haynes et al. 2011), and low-topped and midtopped cloud in the subsiding cold-air section of
TABLE 1. The relative frequency of occurrence (RFO) of the eight Southern Ocean cloud regimes identified in Haynes et al. (2011) within the entire Southern Ocean $\left(30^{\circ}-65^{\circ} \mathrm{S}\right)$ and in the region of interest $50^{\circ}-65^{\circ} \mathrm{S}$ for DJF over the period $1983-2008$. The cloud regimes selected for further study are highlighted in bold.

\begin{tabular}{lccrccccc}
\hline \hline Cloud regime & S1 & S2 & \multicolumn{1}{c}{ S3 } & S4 & S5 & S6 & S7 & S8 \\
\hline $\mathrm{RFO}_{30^{\circ}-65^{\circ} \mathrm{S}}(\%)$ & $\mathbf{3 2 . 4}$ & 8.3 & $\mathbf{1 0 . 3}$ & $\mathbf{1 1 . 5}$ & $\mathbf{1 6 . 4}$ & 8.5 & 8.1 & 4.5 \\
$\mathrm{RFO}_{50^{\circ}-65^{\circ} \mathrm{S}}(\%)$ & $\mathbf{2 2 . 6}$ & 7.2 & $\mathbf{8 . 9}$ & $\mathbf{2 1 . 8}$ & $\mathbf{2 5 . 4}$ & 5.9 & 7.5 & 0.6 \\
\hline
\end{tabular}

extratropical cyclones and leading transient ridges has been implicated as important to the SW model biases (Bodas-Salcedo et al. 2012, 2014).

The mean $\mathrm{CTP}-\tau$ joint histograms and DJF relative frequency of occurrence maps for the selected Southern Ocean cloud regimes are shown in Fig. 2. The ISCCP joint histograms should be interpreted both in light of the passive nature and the horizontal resolution of the original satellite measurements. Blocking of low by high clouds, erroneous CTP estimation in the presence of thin cirrus, and optical thickness underestimation due to partial coverage of pixels with cloud are common limitations encountered (Pincus et al. 2012). A recent evaluation of ISCCP observations over two regions of the tropical Pacific found that cloud-top properties are not a robust predictor of the associated vertical hydrometeor distribution except in the case of deep convective, cirrostratus, and stratocumulus cloud types (Mace and Wrenn 2013). While cloud regime analyses based on these histograms have proved useful in past studies, the degree to which cloud-top properties-and the organization of those properties within the cloud scenes on which we base our cloud regimes-represent consistent vertical cloud structures goes to one of the key problems addressed in this study.

We have selected two low cloud regimes. S1 encompasses instances of low and optically thin cloud. Its high relative frequency of occurrence in the subtropical oceans is associated with instances of trade cumulus, but $\mathrm{S} 1$ is also frequent in the high latitudes. At the scale of ISCCP pixels $(1-4 \mathrm{~km})$ homogeneity is assumed by the retrieval algorithm, such that small clouds like cumulus are identified as optically thin (Pincus et al. 2012): this is likely the case with this cloud regime. Haynes et al. (2011) showed that S1 is a major contributor to the overall $\mathrm{CRE}_{\mathrm{SW}}$ because of its high frequency occurrence. S3 represents deeper low clouds with higher optical thickness and low variance in CTP suggesting homogeneity of cloud-top height at the ISCCP grid scale (i.e., a stratiform cloud). With high frequencies of occurrence at the eastern edge of ocean basins, instances of this cloud regime are related to stable marine boundary layer clouds over cold upwelling currents. 

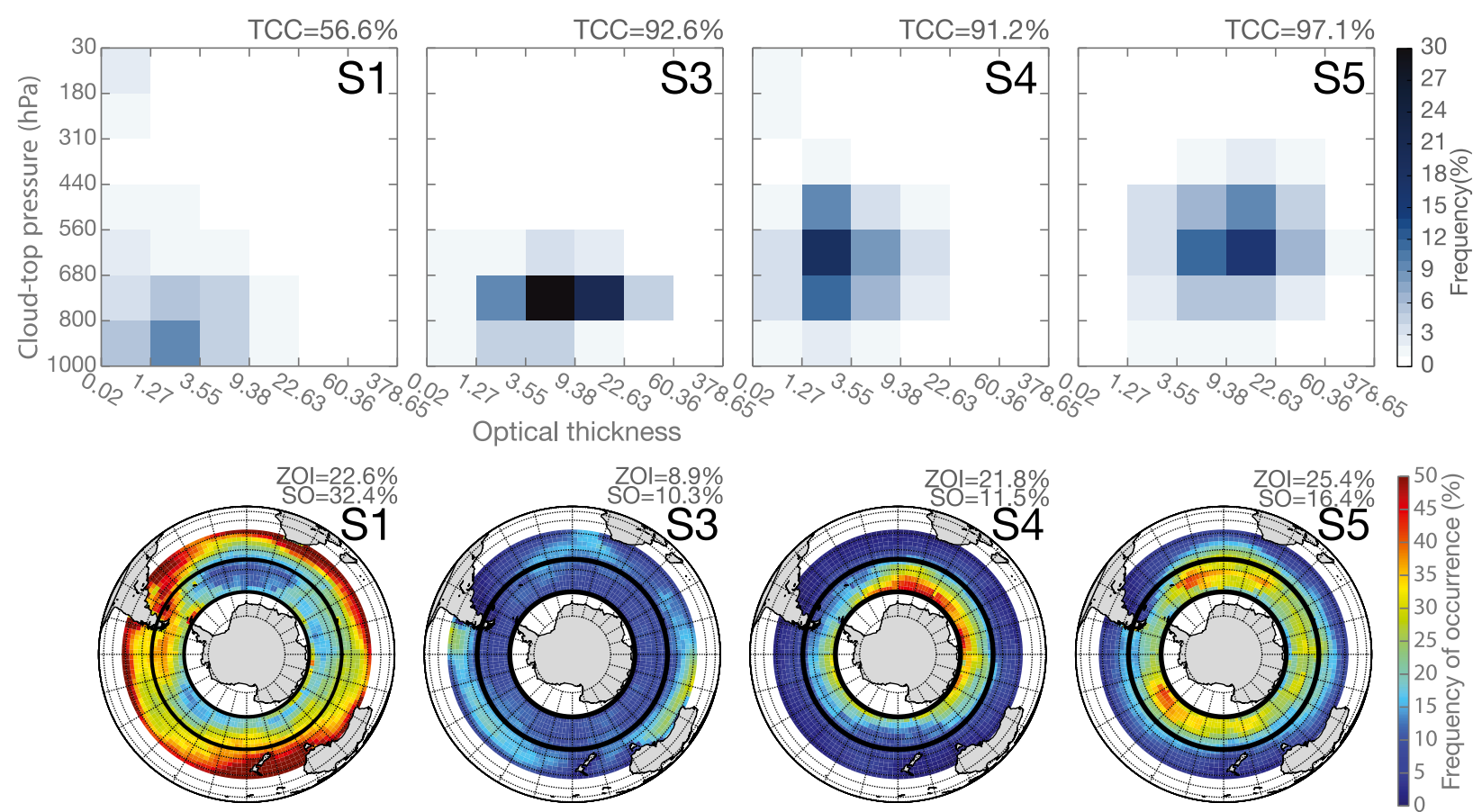

FIG. 2. The low-topped and midtopped Southern Ocean cloud regimes selected according to their frequency of occurrence within the high-latitude Southern Ocean $\left(50^{\circ}-65^{\circ} \mathrm{S}\right)$. (top) Mean CTP- $\tau$ joint histograms for the selected cloud regimes. The sum of each joint histogram gives the total cloud cover (TCC). (bottom) Maps of relative frequency of occurrence for the selected Southern Ocean cloud regimes during austral summer (DJF). The extents of the zone of interest $50^{\circ}-65^{\circ} \mathrm{S}$ are marked with thick black lines; the total frequency of occurrence for the entire Southern Ocean $\left(\mathrm{SO} ; 30^{\circ}-65^{\circ} \mathrm{S}\right)$ and the zone of interest $\left(\mathrm{ZOI} ; 50^{\circ}-65^{\circ} \mathrm{S}\right)$ are given for each cloud regime.

There are two midtopped cloud regimes, which occur most frequently poleward of $50^{\circ} \mathrm{S}$. S4 contains optically thinner clouds and is most frequent at high latitudes nearest the Antarctic continent, with a maximum frequency of occurrence in the southern Pacific Ocean. The high variance in the $\mathrm{CTP}-\tau$ joint histogram suggests that S4 is associated with cloud tops observed concurrently at a range of heights within the ISCCP grid scale: this may suggest broken and/or layered cloud. S5 contains optically thicker and higher clouds than S4, with a maximum frequency of occurrence equatorward of $60^{\circ} \mathrm{S}$, and is especially frequent in the southern Atlantic and Indian Oceans. As an optically thick cloud regime with high CTP variance, S5 resembles a shallower version of the frontal cloud regime S7 (not shown).

\section{b. Vertical pressure velocity as indicator of weather states}

As one of our aims is to study the meteorological conditions associated with the cloud regimes selected above, it is important to verify that they are suitably strong predictors of the state of the atmosphere.

Following the approach of Gordon and Norris (2010), we extract profiles of vertical velocity from reanalysis data in the high-latitude Southern Ocean over the same period for which we have ISCCP observations. The range of profiles associated with each cloud regime is represented by the mean and outer quartiles and deciles of the distribution and compared against the distribution associated with all data over the same region and period (Fig. 3).

The vertical pressure velocities associated with the low cloud regime S1 tend to weak subsidence, including weak ascent and moderate subsidence. S3 is consistently characterized by weak to moderate subsidence. $\mathrm{S} 4$ is associated with a relatively narrow range of vertical pressure velocities, tending to weak subsidence and some weak ascent; the lower variability in the context of this cloud regime suggests S4 is only rarely associated with strongly subsiding conditions. S5 is associated with weak ascent on average but includes a relatively broad range of vertical pressure velocities, including instances of stronger ascent as well as moderate subsidence. As we are particularly interested in the context and properties of midtopped cloud, in the next section we explore the instances of midtopped cloud included within S4 and S5 by performing a refining clustering analysis.

\section{c. Refined midtopped cloud subregimes}

To better differentiate between processes related to midtopped cloud we conduct an additional $k$-means 


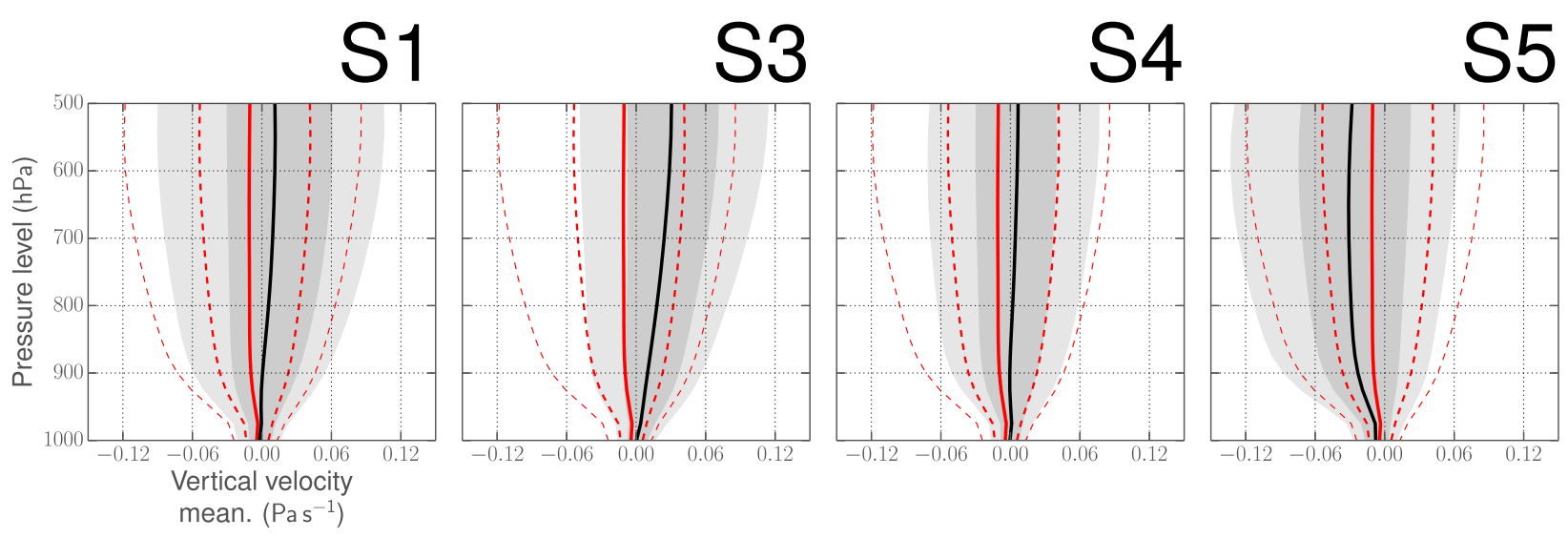

FIG. 3. Profiles of vertical pressure velocity $(\omega)$ below $500 \mathrm{hPa}$ for DJF over the period 1998-2008. Profiles for the cloud regime (black) are compared against all data (red). Dashed lines and shading indicate the outer quartiles and deciles of the distribution. For comparison between cloud regimes the mean and standard deviation of $\omega$ at $600 \mathrm{hPa}$ are given in Table 2 .

clustering analysis on those ISCCP joint histograms already identified as midtopped cloud (i.e., belonging to cloud regimes S4 or S5), calculating self-similar clusters based on the least Euclidean distance between CTP- $\tau$ joint histograms as described in section 2 . We identify four midtopped cloud subregimes M1-M4; as our intention is to distinguish between midtopped cloud types forming under different meteorological conditions, the quasi-objective criteria for selecting the number of subregimes are based on the emergent features in both the $\mathrm{CTP}-\tau$ joint histograms and the associated vertical pressure velocity. The CTP- $\tau$ joint histograms and relative frequency of occurrence distributions for the new cloud subregimes are shown in Fig. 4 together with the two low cloud regimes selected earlier, and Table 2 presents the mean and standard deviation of $600-\mathrm{hPa}$ vertical pressure velocity for the same cloud regimes. Fewer clusters were insufficient to distinguish between structures in the CTP- $\tau$ joint histograms of optically thick midtopped cloud while further increasing the number of clusters added redundant cloud subregimes, which were not further differentiated by their vertical pressure velocities.

As it is of interest to identify the "cloud regime of origin," the fraction of S4 and S5 contributing to each subsequent cloud subregime is indicated in the figure. We find that the optically thin cloud subregime M1 very nearly reproduces $\mathrm{S} 4$, with $88 \%$ of its occurrences drawn from the latter, while M2-M4 constitute subregimes of

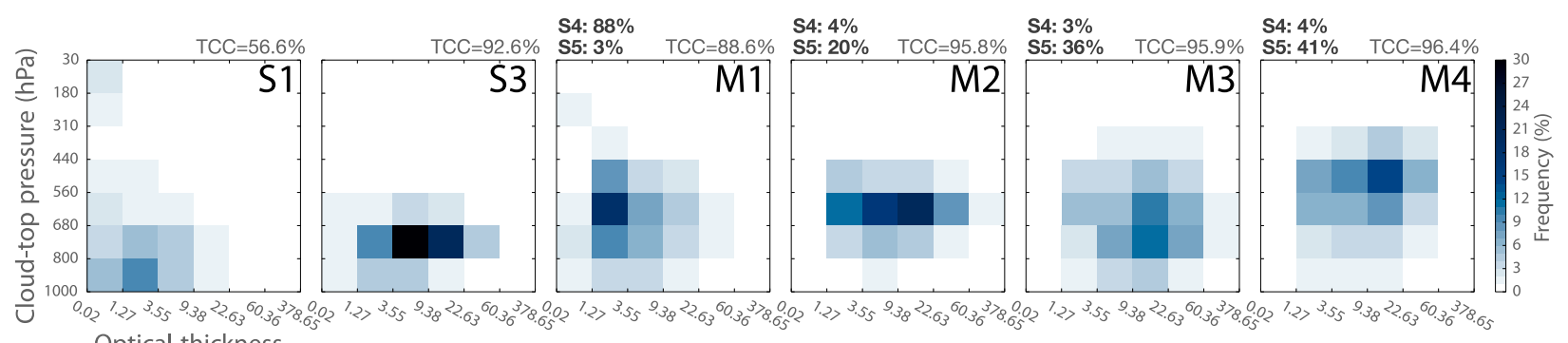
Optical thickness
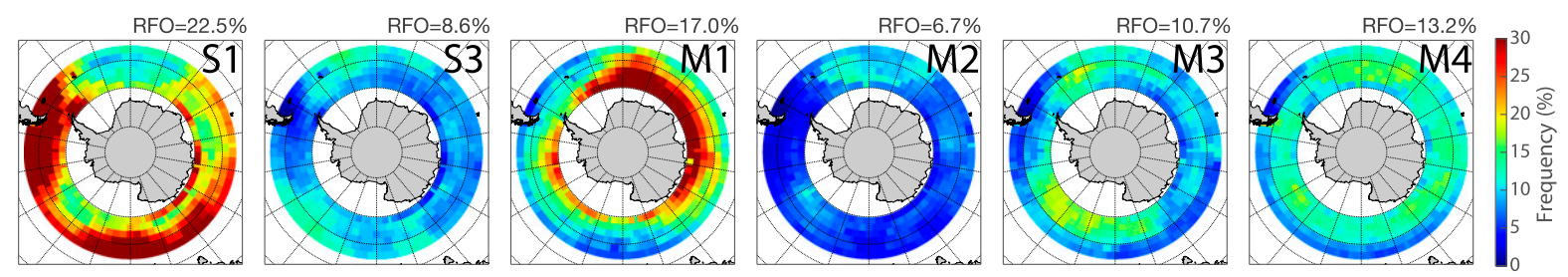

FIG. 4. The selected cloud regimes, including midtopped cloud subregimes. (top) CTP- $\tau$ histograms for the cloud regimes of interest, including refined midtopped cloud regimes (M1-M4). The percentages of the original midtopped cloud regimes (S4 and S5) found in the refined midtopped cloud regimes are indicated. (below) Frequency of occurrence maps for the cloud regimes of interest in the highlatitude Southern Ocean $\left(50^{\circ}-65^{\circ} \mathrm{S}\right)$ during DJF. 
TABLE 2. The mean and standard deviation of $\omega_{600 \mathrm{hPa}}$ for the selected Southern Ocean cloud regimes and the four midtopped cloud subregimes (M1-4) in the region of interest $50^{\circ}-65^{\circ} \mathrm{S}$ for DJF over the period 1983-2008.

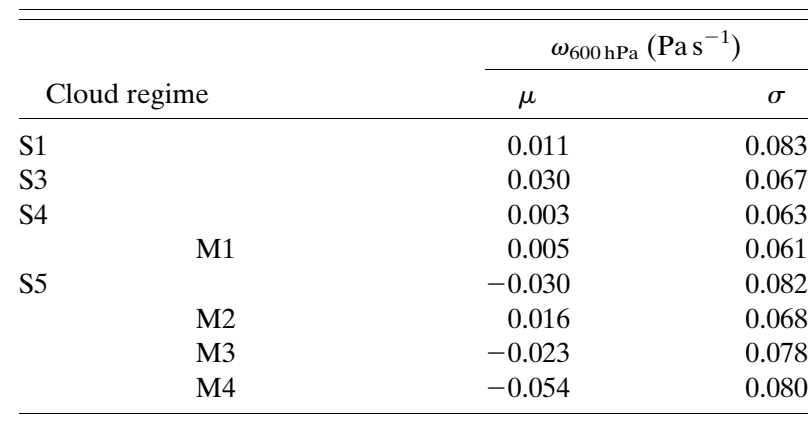

S5, which we noted above was found under a broad range of atmospheric states. This confirms the observation that S5 is not representative of a single weather state but included both consistently subsiding conditions related to M2 (20\% of S5) and the range of weak to moderate ascent characteristic of M3 and M4. This reinforces a caveat often offered when using cloud regimes identified in this way: while often successful in distinguishing cloud types based on cloud-top properties, the cloud regimes cannot be assumed to represent singular or unique weather states.

The CTP $-\tau$ joint histograms of the four midtopped cloud subregime support the finding that M2 is associated with strongly subsiding conditions: the histogram shows low variability in CTP and high values of optical thickness, similar to the stratiform cloud regime S3 but with higher cloud tops. The cloud subregimes associated with mean grid-scale ascent, M3 and M4, have a broader range of CTP and optical thickness in their histograms.

Having identified a refined set of midtopped cloud subregimes, the next sections will more fully characterize the dynamical and thermodynamic conditions associated with each of the cloud regimes in the high-latitude Southern Ocean, as well as further investigate their cloud microphysical and macrophysical structure. For simplicity, we will refer to the new set of cloud regimes as high-latitude Southern Ocean cloud regimes.

\section{The meteorology of the high-latitude Southern Ocean cloud regimes}

The goal of this section is to investigate the meteorological conditions under which the high-latitude Southern Ocean cloud regimes occur. Profiles of several meteorological variables are extracted from reanalysis data according to the concurrent cloud regimes within the zone of interest for DJF over the period 19832008. Profiles of vertical pressure velocity, temperature advection, potential temperature, and relative humidity for the six high-latitude Southern Ocean cloud regimes are shown in Fig. 5.

$\mathrm{S} 1$ is associated with weak ascent to strong subsidence, with cold-air advection and cool potential temperature anomalies at middle levels and dry conditions throughout. Taken together, these conditions suggest that this regime might be related to parts of the cold-air section of extratropical cyclones, as well as a range of low cloud amount scenes.

S3 exhibits very consistent subsidence and cold-air advection near the surface. A strong potential temperature inversion above $900 \mathrm{hPa}$ divides moist cool conditions near the surface from warm and very dry middle levels.

M1 is associated with weak subsidence and cold-air advection below $800 \mathrm{hPa}$. These are similar dynamical conditions to S3; however, M1 is characterized by cold and moist middle levels, with a potential temperature profile indicating unstable atmospheres.

The meteorology associated with M2 resembles that of S3 and M1, with consistent subsidence and strong cold-air advection close to the surface. This corresponds to a relative humidity maximum at a height of $900 \mathrm{hPa}$, between that of S3 and M1. M2 features a strong temperature gradient between 700 and $800 \mathrm{hPa}$. This is similar to S3, with which M2 also shares a low variance of CTP in the CTP- $\tau$ joint histogram, suggesting a stratiform cloud structure.

M3 is associated with a range of weak vertical pressure velocities. With consistently warm anomalies in the middle levels, a relatively strong temperature gradient around $850 \mathrm{hPa}$ separates moist conditions at the surface from drier middle levels. Profiles of temperature advection and humidity are close to the overall mean.

M4 is consistently associated with moderate and strong ascent and warm-air advection, with relatively warm and moist middle levels. In all respects these conditions resemble a weaker and shallower form of those associated with frontal cloud regime (not shown; see Gordon and Norris 2010; Haynes et al. 2011); we note that the meteorological context of this shallow frontal cloud resembles the warm conveyor belt of extratropical cyclones (e.g., Eckhardt et al. 2004).

To gain confidence in the results based on reanalysis data, the analysis was repeated using $25 \mathrm{yr}$ of twice-daily radiosondes from the Australian Antarctic Division weather station at Macquarie Island $\left(54.3^{\circ} \mathrm{S}, 158.57^{\circ} \mathrm{E}\right)$. The profiles of potential temperature and relative humidity at Macquarie Island (not shown) exhibited the same features as found in reanalysis data throughout the high-latitude Southern Ocean, indicating a robust association between the meteorological conditions and cloud structure. 


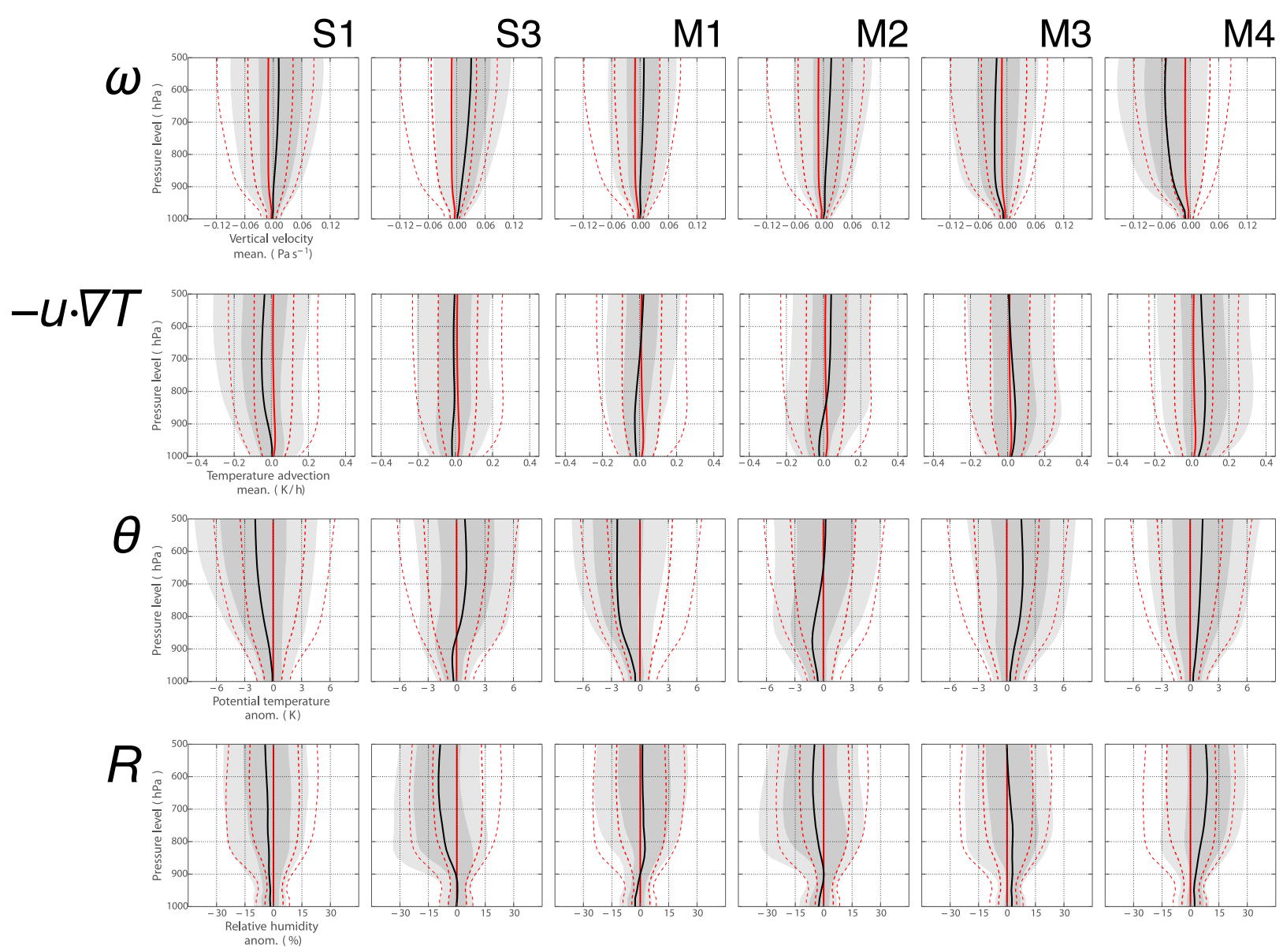

FIG. 5. Profiles below $500 \mathrm{hPa}$ of mean vertical pressure velocity $(\omega)$, mean temperature advection $(-u \cdot \nabla T)$, anomalies of potential temperature $(\theta)$, and anomalies of relative humidity $(R)$ associated with the cloud regimes of interest for DJF during the period 1983-2008. Anomalies are calculated with respect to the local monthly mean at each point (see Gordon and Norris 2010). Black lines and shading indicate the mean and outer deciles and quartiles related to the cloud regime of interest; solid and dashed red lines indicate the mean and outer deciles and quartiles related to all data.

\section{Cloud macrophysics}

Having established the meteorological conditions in which the high-latitude Southern Ocean cloud regimes occur, we proceed to investigate the vertical and microphysical structure of the cloud fields. To do so, we use the merged data product DARDAR (see section 2) to characterize the mean macrophysical properties of the selected cloud regimes and take advantage of the highresolution data to quantify the frequencies of different cloud structures within each cloud regime.

An evaluation of DARDAR against ground-based observations at the Atmospheric Radiation Measurement Program (ARM) station in Darwin have shown that the satellite observations underestimate cloud below $1.50 \mathrm{~km}$ (Protat et al. 2014). This is a considerable limitation over the Southern Ocean, where low cloud is nearly ubiquitous (e.g., Huang et al. 2012b; Haynes et al.
2011). For completeness, DARDAR data are still used below $1.50 \mathrm{~km}$; however, in all graphs this part of the profile is stippled to indicate considerable uncertainty at these levels.

We define cloud as any pixel in which the DARDAR phase category mask identifies ICE, ICE + SLW, SLW, WLW, or RAIN. The unknown category is included as an upper estimate of cloud frequency where lidar attenuation inhibits cloud phase classification.

Figure 6 shows the vertical profile of cloud frequency of occurrence concurrent to the cloud regimes of interest. All of the midtopped cloud regimes feature significant low cloud, with frequency of occurrence maxima below $2 \mathrm{~km}$; this is in agreement with the discussion in Haynes et al. (2011) for the midlevel cloud regimes.

The cloud regimes S3 and M2, which are related to consistent subsidence, have profiles indicating dominant low cloud decks, with M2 characterized by higher cloud 


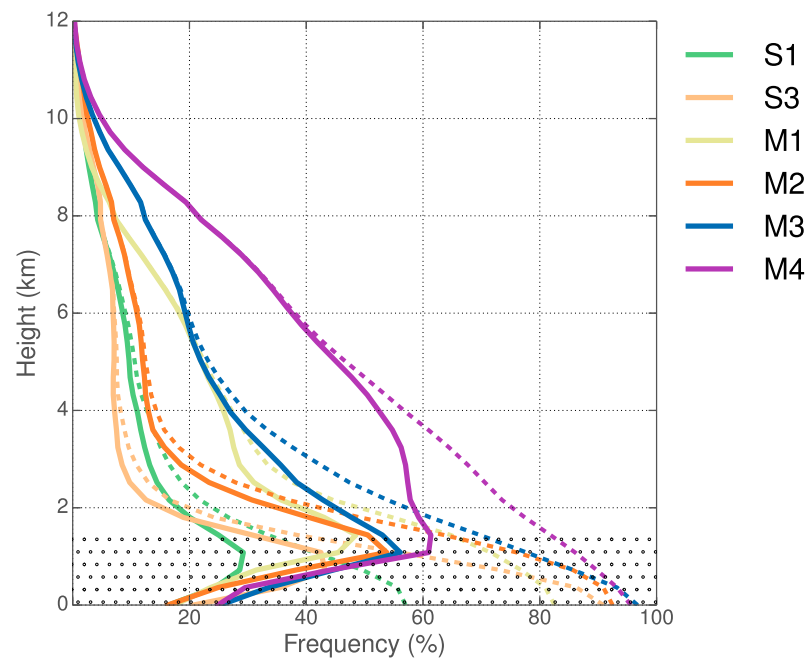

FIG. 6. Profiles of mean cloud fraction from DARDAR phase categories, concurrent to the cloud regimes of interest. Dashed lines indicate the upper estimate of cloud frequency including the unknown category. The lowest $1.50 \mathrm{~km}$ of the profile is stippled to indicate a known underestimate of cloud frequency of occurrence.

tops than S3. M1 and M3 have similar amounts of lowlevel and midlevel cloud but, while the cloud frequency of occurrence related to M3 reduces mostly monotonically with height, M1 has a bimodal distribution that may indicate the presence of characteristic midlevel cloud layers. M4 is distinguished from the other midtopped cloud regimes by the high frequency of midlevel cloud above $3 \mathrm{~km}$. The apparent steep reduction of cloud fraction below around $1.50 \mathrm{~km}$ for all cloud regimes is consistent with the underestimation of cloud near the surface identified in Protat et al. (2014).

While the mean profiles of cloud frequency of occurrence differentiate the cloud regimes, they do not retain information on the vertical cloud structures or their variability within the cloud regimes: Is the midlevel cloud contiguous from low levels (e.g., congestus), or does it occur as a discrete layer (e.g., altostratus)? Are midtopped and low cloud layers collocated or distinct? In addition to the mean macrophysical properties of each cloud regime, we can take advantage of 1-km horizontalresolution active satellite observations to classify discrete vertical layers of cloud and quantify their frequencies of occurrence.

First, we define eight coarse classes of instantaneous vertical cloud structure based on a similar analysis in Bodas-Salcedo et al. (2014). Each DARDAR pixel identified as containing cloud is grouped into one of three coarse height categories (low cloud is less than $3.40 \mathrm{~km}$; high cloud is higher than $6.80 \mathrm{~km}$ ), and the cloud structure for each DARDAR pixel is categorized by the concurrent occurrence of clouds at each height.
Figure 7 shows the relative frequency of each of the macrophysical structure categories within the cloud regimes of interest.

S1 is mostly comprised of either clear conditions $(25 \%)$ or low cloud only $(45 \%)$. S3 is consistently characterized by low cloud only $(70 \%)$. With the exception of M4, the midtopped cloud subregimes consist of more low cloud in isolation $(40 \%-60 \%)$ than concurrent with midlevel cloud, and none of the midtopped cloud subregimes is frequently associated with midlevel cloud in isolation. Unlike the other cloud regimes identified as midtopped by ISCCP, M4 is dominated by occurrences of midlevel cloud in conjunction with low cloud $(35 \%)$ and with cloud at all levels $(40 \%)$.

These cloud structure categories give a good indication of the frequency of cloud structures at very coarse resolution but cannot distinguish between deep and thin clouds or identify layered cloud at different levels. To investigate the cloud structure in more detail, contiguous pixels of known cloud phase classes within each DARDAR granule were identified as discrete clouds, and cloud-top height and physical thickness statistics for all clouds were then collated through all DARDAR granules and grouped by cloud regime. The unknown category is not included here in order to avoid cases where lidar extinction through a liquid cloud layer are misidentified as contiguous cloud extending to the surface. Figure 8 shows joint histograms of cloud-top height and physical cloud thickness within the cloud regimes of interest. Three sections of the joint histograms describe distinct cloud structures: in the bottomleft corner are boundary layer clouds, along the vertical axis are physically thin clouds (e.g., altostratus), and the diagonal represents physically deep clouds extending from near the surface to their respective cloud-top heights (e.g., congestus)

All cloud regimes exhibit frequent low clouds below $3 \mathrm{~km}$, confirming the ubiquity of boundary layer cloud in the Southern Ocean, and physically thin clouds are commonly found at all heights. S1 consists almost entirely of thin low cloud below $3 \mathrm{~km}$, with infrequent thin clouds at all levels. This is expected for a cloud regime associated with shallow cumulus and a broad range of mostly clear conditions. S3 is dominated by deeper low clouds and exhibits fewer thin clouds at middle levels. M1 is dominated by frequent thin clouds along the vertical axis, with a minor secondary maximum in the middle levels; this cloud subregime also includes some deeper midtopped clouds along the diagonal. M2 includes deeper and higher clouds than S3, with more frequent thin and deep clouds below $4 \mathrm{~km}$ but relatively infrequent midlevel deep or layered clouds. M3 combines frequent thin clouds below $5 \mathrm{~km}$ and deep midtop 


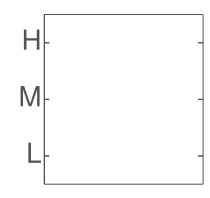

RFO $=7.5 \%$
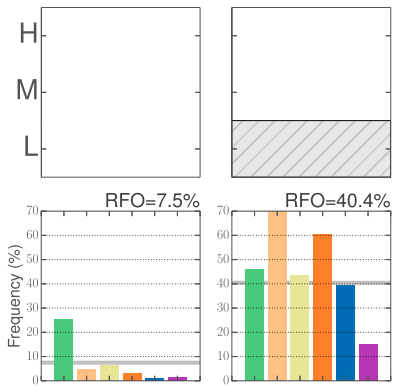

$\mathrm{RFO}=40.4 \%$
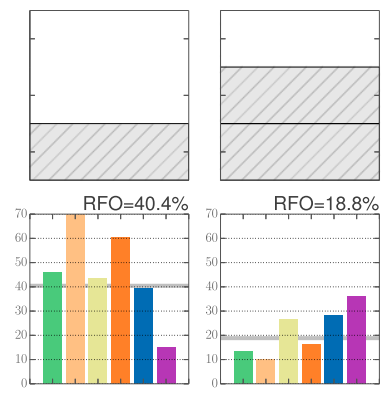

$\mathrm{RFO}=18.8 \%$
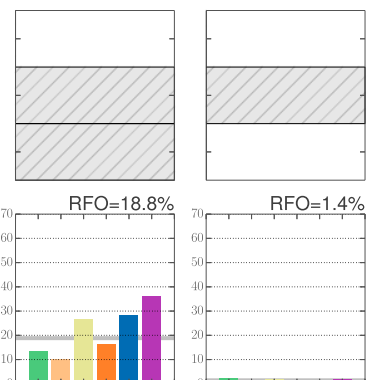

$\mathrm{RFO}=1.4 \%$
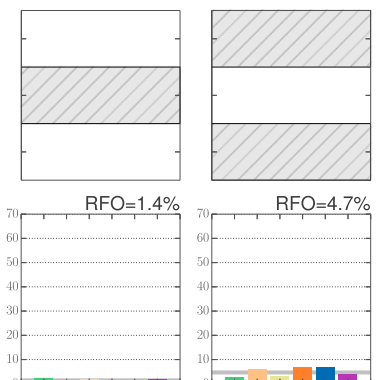

RFO $=4.7 \%$
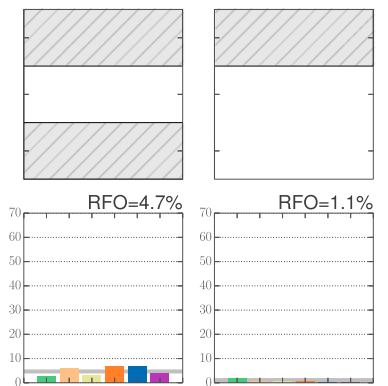

$\mathrm{RFO}=1.1 \%$
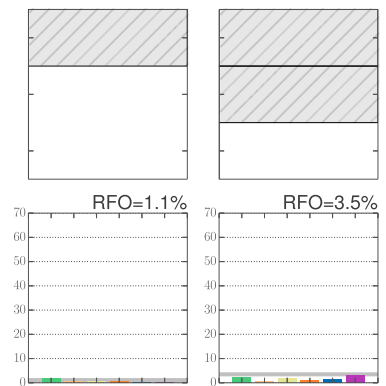

$\mathrm{RFO}=3.5 \%$
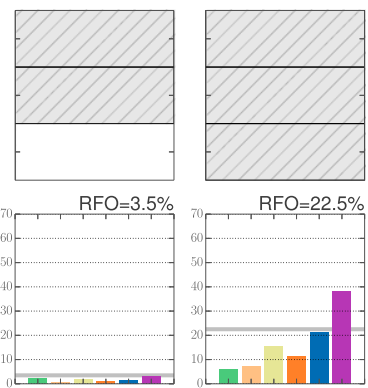

$\mathrm{RFO}=22.5 \%$

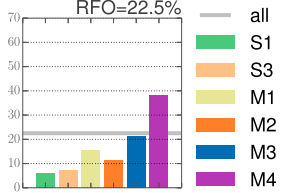

FIG. 7. Frequency of occurrence of eight cloud structure classifications based on the occurrence of DARDAR cloud phase classifications at three coarsely defined height categories (low, midlevel, and high cloud) within the cloud regimes of interest in the high-latitude Southern Ocean during DJF. The overall relative frequency of occurrence of each cloud structure classification is given and indicated by gray horizontal lines.

clouds along the diagonal; M3 is differentiated from M1 by its deeper midtopped cloud structures. M4 is clearly distinguished from the other midtopped cloud regimes by its high frequency of both thin midlevel cloud along the vertical axis and deep clouds with tops between 4 and $7 \mathrm{~km}$.

Using a series of analyses of macrophysical cloud structure we have confirmed the ubiquity of low cloud within the midtopped cloud subregimes, but we can also successfully distinguish between midlevel cloud dominated by thin cloud in layered scenes and those representing deeper midtopped clouds. We note a correspondence of deep clouds in cloud regimes related to large-scale ascent and high optical thickness and of thinner cloud layers with subsiding conditions and optically thinner cloud regimes.

\section{Cloud microphysics}

In addition to the macrophysical cloud structure, we can make use of the DARDAR cloud phase classification to investigate some of the microphysical characteristics of the cloud regimes of interest. The occurrence of SLW-in isolation and in mixed-phase cloud-is particularly pertinent in the Southern Ocean, where relatively high amounts of SLW are known to occur in cloud tops between $-10^{\circ}$ and $-20^{\circ} \mathrm{C}$ (Morrison et al. 2011; Huang et al. 2012b).

Frequencies of occurrence of DARDAR cloud phase categories are grouped by cloud regime to derive vertical histograms of each cloud phase. The unknown phase category is included, as it can relate to parts of the vertical profile for which retrievals are unavailable because of lidar extinction through optically thick clouds, limited radar sensitivity to small cloud droplets, and radar signal contamination by ground clutter. Figure 9 shows cloud phase frequency of occurrence for each cloud regime as a function of height and of atmospheric temperature derived from ECMWF data included in the DARDAR data product.

The cumulus cloud regime $\mathrm{S} 1$ has a maximum cloud frequency of occurrence around $1 \mathrm{~km}$ and between $0^{\circ}$ and $-10^{\circ} \mathrm{C}$, where mixed-phase and SLW cloud represent more than $30 \%$ of the known cloud phase. The stratiform cloud regime $\mathrm{S} 3$ exhibits a more distinct cloud deck below $2 \mathrm{~km}$ and between $0^{\circ}$ and $-10^{\circ} \mathrm{C}$, where SLW and mixedphase cloud represent close to $50 \%$ of the known cloud phase.

The midtopped cloud subregimes associated with weak and moderate subsidence, M1 and M2, have distinct cloud maxima between 1 and $2 \mathrm{~km}$ and around $-10^{\circ} \mathrm{C}$; SLW is consistently found between $0^{\circ}$ and $-10^{\circ} \mathrm{C}$, and both cloud subregimes have peaks of mixed-phase cloud between $-10^{\circ}$ and $-15^{\circ} \mathrm{C}$, indicative of cold stratiform cloud tops.

The midtopped cloud subregimes associated with weak and moderate ascent, M3 and M4, have less distinct cloud frequency maxima, and the distribution of mixed-phase cloud throughout the middle levels - as cold as $-35^{\circ} \mathrm{C}$ likely indicates convective processes associated with these cloud regimes. The relatively high frequencies of WLW and liquid rain are indicative of warmer conditions, reinforcing the frontal conditions associated with M4 in particular. M4 is distinguished from the other midtopped cloud subregimes by the high frequency of ice and mixed-phase cloud throughout the middle levels as compared to low cloud.

The mean histograms of cloud phase with temperature and height represent the average cloud microphysical properties at the scale of ISCCP cloud regimes but do not describe cloud structure or microphysics on the scale of cloud processes. We can use high-resolution and instantaneous DARDAR profiles to identify recurring cloud structures; the frequency of occurrence of these instantaneous cloud structure classes quantify the variability of cloud structures on the horizontal scale of 

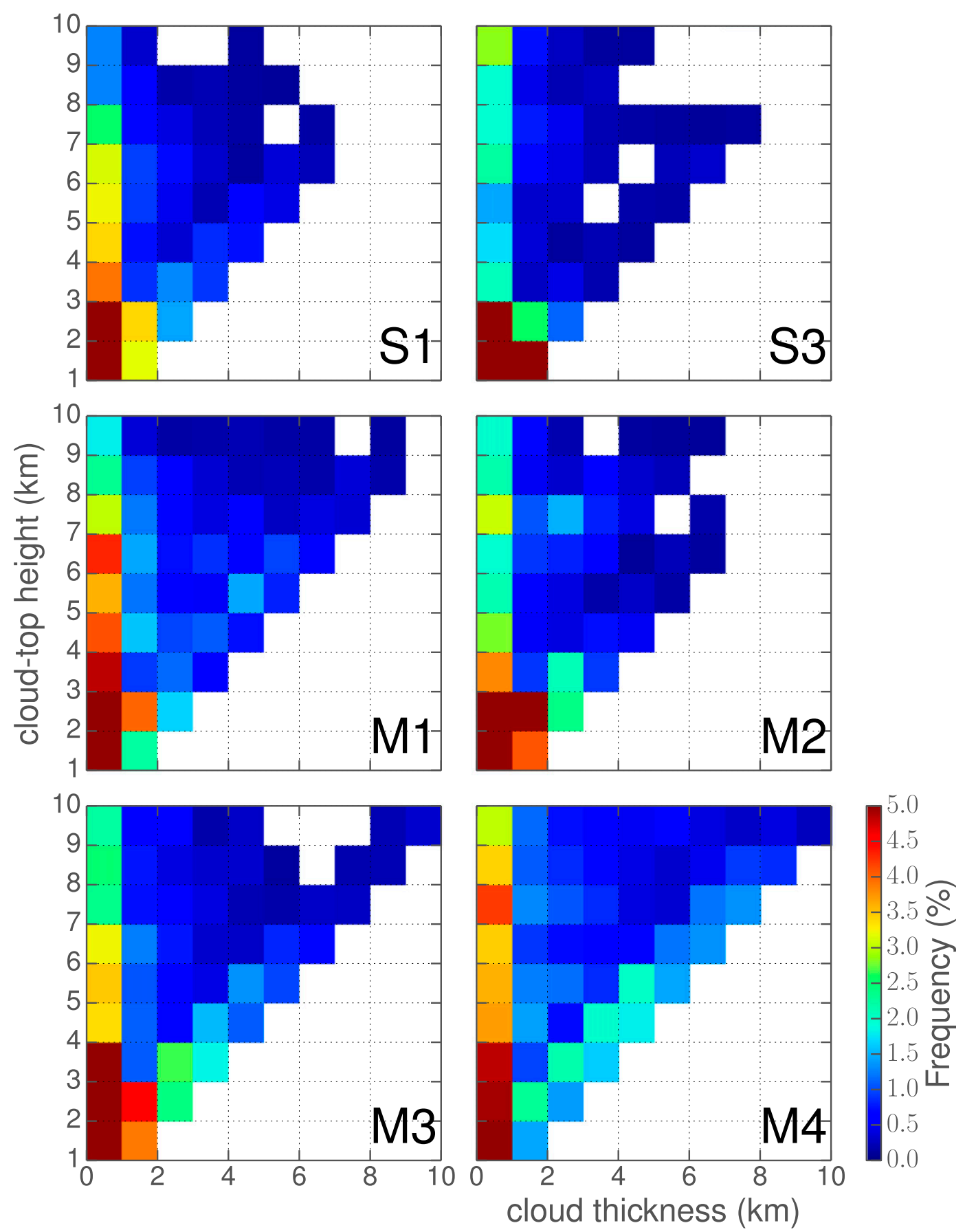

FIG. 8. Joint histograms of cloud-top height and physical cloud thickness derived from profiles of contiguous cloud identified from the DARDAR cloud classification mask through the cloud regimes of interest.

$1 \mathrm{~km}$ within the coarse horizontal scales of the ISCCP cloud regimes.

To identify a small number of representative cloud macro and microphysical profiles, a $k$-means clustering algorithm is applied to the vertical histograms of the frequency of occurrence of each cloud phase classification using $2^{\circ} \mathrm{C}$ bins of atmospheric temperature from the collocated ECMWF temperature field between $-80^{\circ}$ and $30^{\circ} \mathrm{C}$. As a result, the state vector for the cluster analysis consists of 6 phase categories in 54 temperature bins: hence, a total length of 324 . Cloud phase classification histograms were calculated for each DARDAR profile in the area of interest for DJF during the period 2006-08. DARDAR's unknown cloud phase classification is 

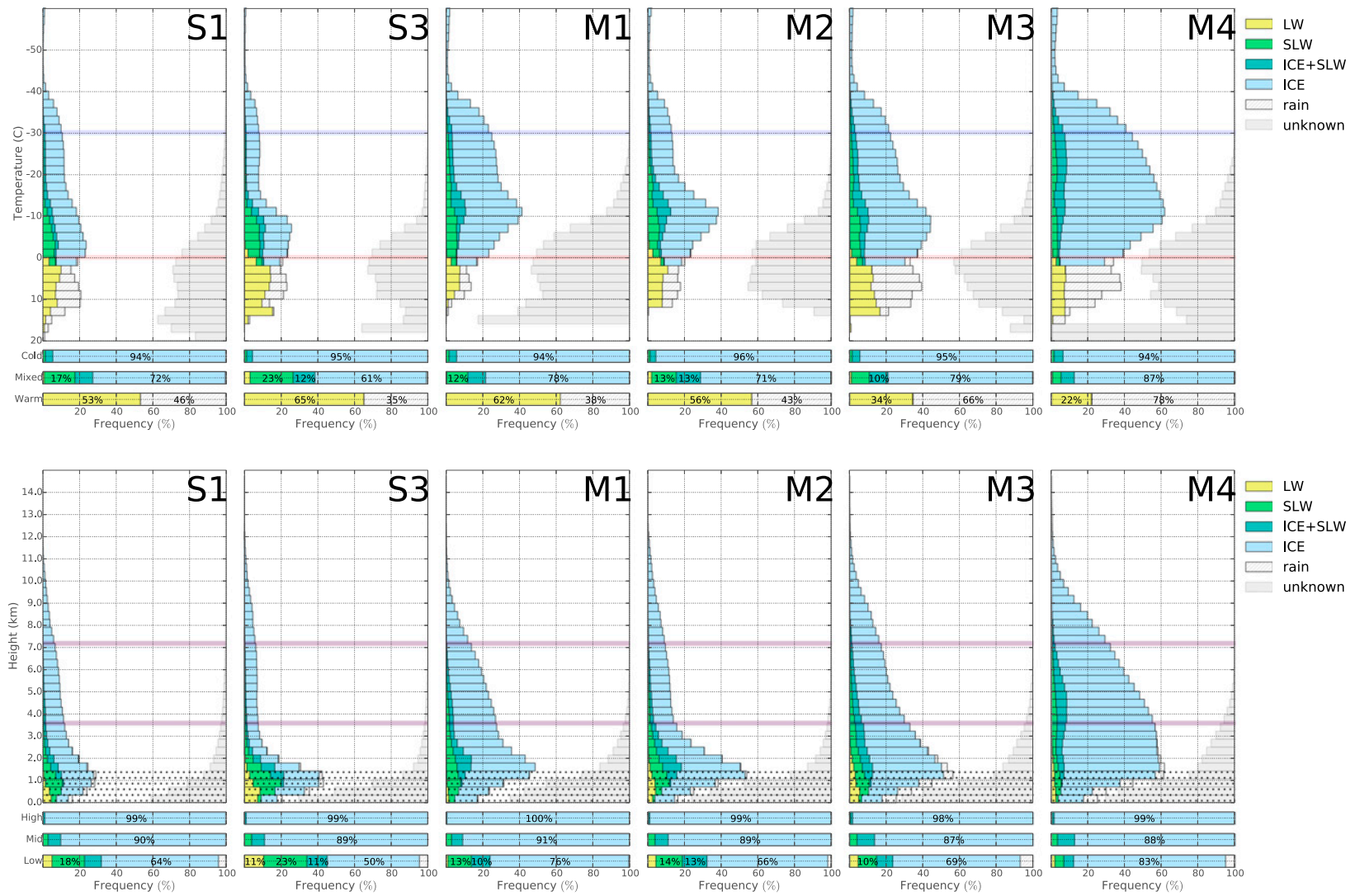

FIG. 9. The absolute frequency of occurrence of DARDAR cloud phase classifications (including unknown) within each cloud regime of interest. (top) Cloud phase histograms according to height; the lower part of each panel shows the relative frequency of occurrence of known cloud phase classification (not including unknown) in three coarsely defined height categories (high: $h>7.20 \mathrm{~km}$; mid: $7.20 \mathrm{~km}>$ $h>3.60 \mathrm{~km}$; low: $h<3.60 \mathrm{~km}$ ) demarked by gray lines. The section below $1.50 \mathrm{~km}$ is stippled to indicate known underrepresentation of cloud close to the surface. (bottom) Cloud phase histograms presented according to atmospheric temperature; the lower part of each panel shows the relative frequencies of occurrence for known cloud phase classification in three coarsely defined temperature categories (cold: $T<-30^{\circ} \mathrm{C}$; mixed: $-30^{\circ} \mathrm{C}<T<0^{\circ} \mathrm{C}$; warm: $T>0^{\circ} \mathrm{C}$ ) demarked by red and blue lines.

included as it retains information about the extinction of lidar signal through optically thick liquid water cloud. Histograms of cloud phase frequency of occurrence were binned by temperature rather than directly by height because temperature is the main determinant of cloud thermodynamic phase; corresponding histograms of cloud phase classification by height are subsequently calculated on 360-m bins from the cloud structure profiles belonging to each cluster. We note that the cloud structure classes are defined by cluster centroids which represent the mean values of all the cloud phase classification histograms grouped by the clustering algorithm: individual instantaneous profiles are assigned to the cluster centroid from which they differ by the least Euclidean distance. The algorithm requires the prescription of the number of states (clusters) generated: given our goal of identifying a relatively small number of broad recurring classes of cloud structure, 10 classes offered sufficient detail for our investigation; fewer classes did not capture the range of cloud structures, while additional classes resulted in redundant information.

The cloud structure classes, presented as histograms of cloud phase classification by temperature and height and their relative frequencies of occurrence within the cloud regimes of interest, are shown in Fig. 10.

$\mathrm{P} 1$ represents partial cloud below $1 \mathrm{~km}$ with high instances of liquid water; it includes thin low clouds as well as mostly clear profiles. This cloud structure represents around $30 \%$ of all DARDAR profiles in the region of interest and is a major component of the shallow cumulus cloud regime S1 (60\%) and the stratiform cloud regime S3 (45\%).

P2 represents low and shallow cloud containing significant supercooled liquid and mixed-phase water, with tops below $2 \mathrm{~km}$ and around $-10^{\circ} \mathrm{C}$. This cloud structure profile is most frequent within stratiform cloud regimes associated with subsidence: S3 (35\%), M2 (30\%), and M1 (25\%). 

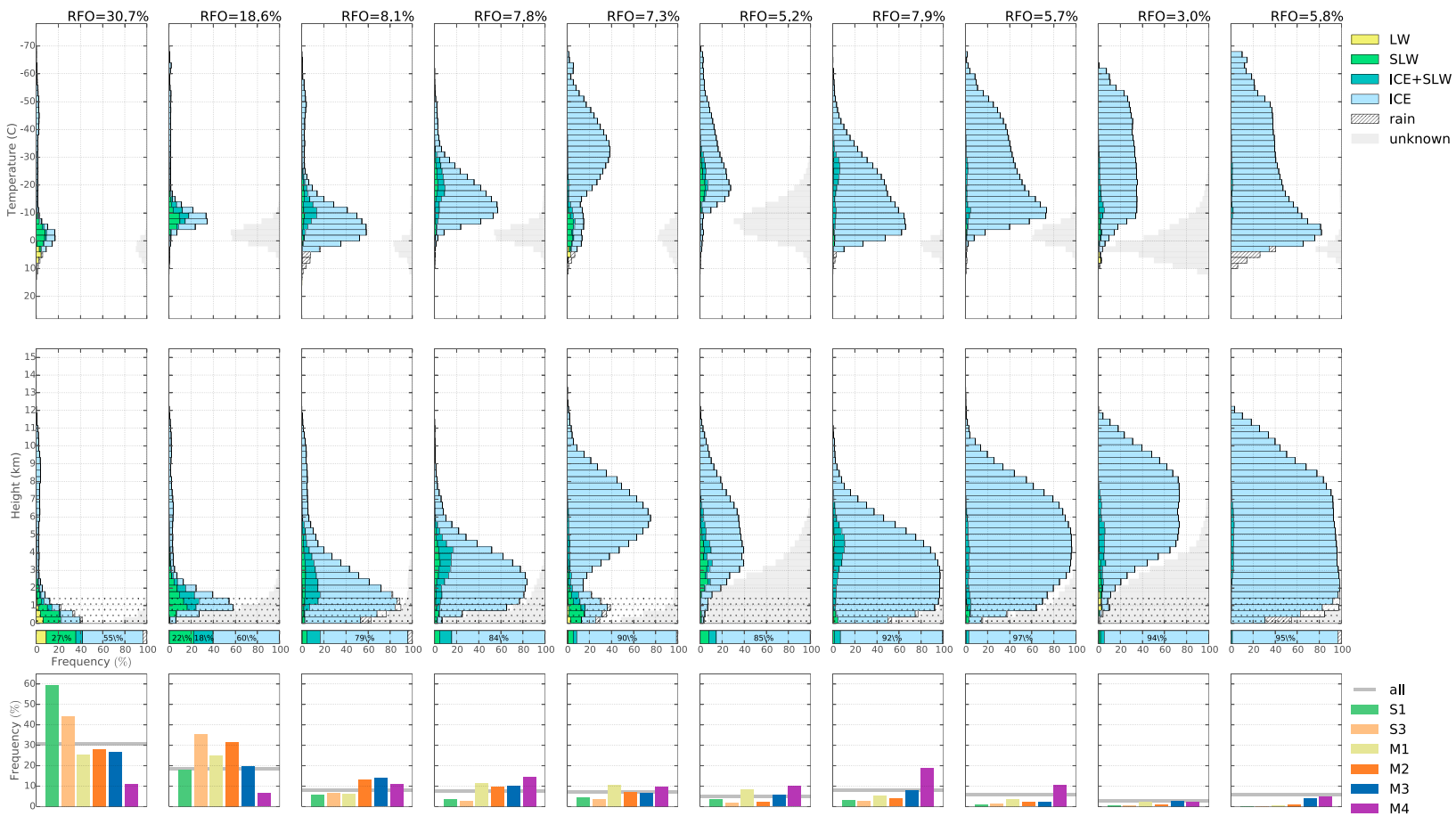

FIG. 10. Instantaneous cloud structure classes displayed according to (top) atmospheric temperature and (middle) height. The bar charts represent the distribution of known DARDAR cloud phase categories within each cloud structure class. To indicate radar signal contamination near the ground, the lowest $1.50 \mathrm{~km}$ of the height profiles are stippled. (bottom) The column chart indicates the relative frequency of occurrence of each cloud structure class within the cloud regimes of interest; the overall relative frequency of occurrence of each cloud structure is marked with a gray line.

P3 and P4 represent physically thicker low-topped to midtopped cloud layers with frequent mixed-phase water near cloud top. The warmer cloud structure P3, with mixed-phase tops around $-10^{\circ} \mathrm{C}$, is found most often in the optically thick midtopped cloud subregimes M2-M4; the colder cloud structure $\mathrm{P} 4$, with mixed-phase and SLW cloud between $-15^{\circ}$ and $-30^{\circ} \mathrm{C}$, is most frequent in M1 and M4.

P5 combines layers of ice cloud between 4 and $8 \mathrm{~km}$ with low cloud with tops below $2 \mathrm{~km}$, including a prominent band of supercooled liquid water below $-10^{\circ} \mathrm{C}$. P6 includes ice cloud throughout the middle levels, with significant supercooled liquid water between $-10^{\circ}$ and $-30^{\circ} \mathrm{C}$; the prevalence of the unknown category below $-10^{\circ} \mathrm{C}$ indicates almost total lidar extinction below the liquid water layer, which may obscure concurrent low cloud. These midlevel layered cloud phase profiles are most frequent in M1 and M4, which are both associated with the most frequent thin midtopped cloud in Fig. 8.

P7-P10 represent deep contiguous clouds with tops through the middle and upper levels; they are dominated by ice water, but mixed-phase cloud through temperatures as cold as $-35^{\circ} \mathrm{C}$ is indicative of convective processes. The midtopped cloud structures contribute around $30 \%$ of the midtopped cloud subregime M4, while the deepest are found predominantly in the deep frontal cloud regime (not shown).

This high-resolution approach to describing the macro and microphysical cloud structures provides a measure of the subgrid-scale variability within the ISCCP cloud regimes. This is particularly relevant for the midtopped cloud subregimes that include combinations of low and thin cloud, deeper low-topped to midtopped clouds, and midlevel cloud layers above low cloud. The variability of cloud structures within a cloud regime may be characteristic of inherently complex structures such as those related to convection, or may indicate mesoscale features embedded below the ISCCP grid scale. Further work would be required to relate these high-resolution physical cloud structures to contemporary dynamical and thermodynamical conditions at finer scales.

\section{Summary and discussion}

Positive SW radiation biases over the high-latitude Southern Ocean are among the most common in global climate model intercomparisons. Previous studies have attributed the biases to the representation of midtopped cloud regimes in the region. The method of using passive satellite observations to identify cloud regimes is well 
established and, used broadly, has proved useful. However, a coherent description of these midtopped cloud regimes-their meteorological contexts, macrophysical structures, and microphysical properties-has not yet emerged. Recent model evaluation methods focused on Southern Ocean cloud have identified a single midtopped cloud regime based on mean cloud-top properties (e.g., Williams and Webb 2009; Bodas-Salcedo et al. 2012, 2014), while observational studies of the same area have distinguished between two midtopped cloud regimes (Haynes et al. 2011; Oreopoulos and Rossow 2011).

We have demonstrated that the existing midtopped cloud regimes derived for the Southern Ocean do not describe sufficiently coherent meteorological contexts to be useful in identifying key cloud processes and properties within the zone of interest $\left(50^{\circ}-65^{\circ} \mathrm{S}\right)$. A refined set of midtopped cloud subregimes was found to more clearly differentiate between meteorological contexts and cloud macrophysical structure and microphysical properties. We combine these refined cloud regimes with a cloud phase classification mask from active satellite observations to characterize the physical cloud structures and distribution of cloud thermodynamic phase at high resolution within each cloud regime.

Using high-resolution lidar and radar observations at horizontal scales of $1 \mathrm{~km}$ to interrogate the structure of cloud regimes identified at a scale of $280 \mathrm{~km}$, we have illustrated issues of scale when using ISCCP observations to identify cloud processes: for example, it seems likely that mesoscale processes such as mesocyclones ("polar lows") contribute to the deep cloud structures embedded within key midtopped cloud subregimes but that these features would be unresolved at the scale of ISCCP observations. This is supported by Mace and Wrenn (2013), which showed that the vertical hydrometeor occurrence associated with ISCCP cloud-top properties were only consistent for observations in the deep convection, cirrostratus, and stratocumulus sections of the joint $\mathrm{CTP}-\tau$ histogram: that is, for reasonably optically thick cloud types with organized cloud-top structures on the scale of ISCCP observations.

We note that further work is required to implement process-resolving cloud regimes in model evaluation studies. Recent studies in the context of composite cyclones have used a single midtopped cloud regime (Bodas-Salcedo et al. 2012, 2014); we have shown that cloud identified as midtopped by ISCCP can be divided in to physically distinct cloud subregimes occurring in meteorological contexts resembling the subsiding coldair section, as well as the warm conveyor belt, of extratropical cyclones. Further work is required to explore the organization of midtopped cloud in this and other contexts with respect to the SW biases in global climate models.

We have demonstrated that ISCCP cloud regimes are useful when applied with caution. In this application, refined cloud regimes can be used to differentiate between key cloud structures, microphysical properties, and meteorological processes in the high-latitude Southern Ocean, which should prove useful in model evaluation and attribution of the Southern Ocean SW radiation biases.

Acknowledgments. This research has been supported by ARC Discovery and Linkage Grant Schemes (DP130100869 and LP0883961) as well as the ARC Centre of Excellence for Climate System Science (CE110001028). CloudSat and CALIPSO data were provided by NASA/ CNES and we thank the ICARE Data and Services Center (http://www.icare.univ-lille1.fr) for providing access to the data used in this study. We thank John Haynes for many fruitful discussions about his work on Southern Ocean cloud regimes and three anonymous reviewers, whose contributions strengthened this study considerably.

\section{REFERENCES}

Anderberg, M., 1973: Cluster Analysis for Applications. Academic Press, 359 pp.

Bodas-Salcedo, A., K. D. Williams, P. R. Field, and A. P. Lock, 2012: The surface downwelling solar radiation surplus over the Southern Ocean in the Met Office model: The role of midlatitude cyclone clouds. J. Climate, 25, 7467-7486, doi:10.1175/ JCLI-D-11-00702.1.

— , and Coauthors, 2014: Origins of the solar radiation biases over the Southern Ocean in CFMIP2 models. J. Climate, 27, 41-56, doi:10.1175/JCLI-D-13-00169.1.

Boers, R., J. B. Jensen, P. B. Krummel, and H. Gerber, 1996: Microphysical and short-wave radiative structure of wintertime stratocumulus clouds over the Southern Ocean. Quart. J. Roy. Meteor. Soc., 122, 1307-1339, doi:10.1002/qj.49712253405.

,$- \ldots$, and - 1998: Microphysical and short-wave radiative structure of stratocumulus clouds over the Southern Ocean: Summer results and seasonal differences. Quart. J. Roy. Meteor. Soc., 124, 151-168, doi:10.1002/qj.49712454507.

Ceppi, P., Y.-T. Hwang, X. Liu, D. M. Frierson, and D. L. Hartmann, 2013: The relationship between the ITCZ and the Southern Hemispheric eddy-driven jet. J. Geophys. Res., 118, 5136-5146, doi:10.1002/jgrd.50461.

Dee, D. P., and Coauthors, 2011: The ERA-Interim reanalysis: Configuration and performance of the data assimilation system. Quart. J. Roy. Meteor. Soc., 137, 553-597, doi:10.1002/qj.828.

Delanoë, J., and R. J. Hogan, 2010: Combined CloudSatCALIPSO-MODIS retrievals of the properties of ice clouds. J. Geophys. Res., 115, D00H29, doi:10.1029/2009JD012346.

Donohoe, A., and D. S. Battisti, 2012: What determines meridional heat transport in climate models? J. Climate, 25, 3832-3850, doi:10.1175/JCLI-D-11-00257.1.

Eckhardt, S., A. Stohl, H. Wernli, P. James, C. Forster, and N. Spichtinger, 2004: A 15-year climatology of warm conveyor 
belts. J. Climate, 17, doi:10.1175/1520-0442(2004)017<0218: AYCOWC $>2.0 . \mathrm{CO} ; 2$.

Fitzpatrick, M., and S. Warren, 2007: The relative importance of clouds and sea ice for the solar energy budget of the Southern Ocean. J. Climate, 20, 941-954, doi:10.1175/JCLI4040.1.

Gordon, N. D., and J. R. Norris, 2010: Cluster analysis of midlatitude oceanic cloud regimes: Mean properties and temperature sensitivity. Atmos. Chem. Phys., 10, 6435-6459, doi:10.5194/ acp-10-6435-2010.

,,-- C. P. Weaver, and S. A. Klein, 2005: Cluster analysis of cloud regimes and characteristic dynamics of midlatitude synoptic systems in observations and a model. J. Geophys. Res., 110, D15S17, doi:10.1029/2004JD005027.

Haynes, J. M., C. Jakob, W. B. Rossow, G. Tselioudis, and J. R. Brown, 2011: Major characteristics of Southern Ocean cloud regimes and their effects on the energy budget. J. Climate, $\mathbf{2 4}$, 5061-5080, doi:10.1175/2011JCLI4052.1.

Huang, Y., S. T. Siems, M. J. Manton, L. B. Hande, and J. M. Haynes, 2012a: The structure of low-altitude clouds over the Southern Ocean as seen by CloudSat. J. Climate, 25, 25352546, doi:10.1175/JCLI-D-11-00131.1.

,,,--- A. Protat, and J. Delanoë, 2012b: A study on the low-altitude clouds over the Southern Ocean using the DARDAR-MASK. J. Geophys. Res., 117, D18204, doi:10.1029/ 2012JD017800.

Hwang, Y.-T., and D. M. W. Frierson, 2013: Link between the double-intertropical convergence zone problem and cloud biases over the Southern Ocean. Proc. Natl. Acad. Sci. USA, 110, 4935-4940, doi:10.1073/pnas.1213302110.

Jakob, C., G. Tselioudis, and T. Hume, 2005: The radiative, cloud, and thermodynamic properties of the major tropical western Pacific cloud regimes. J. Climate, 18, 1203-1215, doi:10.1175/ JCLI3326.1.

Li, J.-L. F., D. E. Waliser, G. Stephens, S. Lee, T. L'Ecuyer, S. Kato, N. Loeb, and H.-Y. Ma, 2013: Characterizing and understanding radiation budget biases in CMIP3/CMIP5 GCMs, contemporary GCM, and reanalysis. J. Geophys. Res., 118, 8166-8184, doi:10.1002/jgrd.50378.

Loeb, N. G., B. A. Wielicki, D. R. Doelling, G. L. Smith, D. F. Keyes, S. Kato, N. Manalo-Smith, and T. Wong, 2009: Toward optimal closure of the earth's top-of-atmosphere radiation budget. J. Climate, 22, 748-766, doi:10.1175/2008JCLI2637.1.

Mace, G. G., 2010: Cloud properties and radiative forcing over the maritime storm tracks of the Southern Ocean and North Atlantic derived from A-Train. J. Geophys. Res., 115, D10201, doi:10.1029/2009JD012517.

—, and F. J. Wrenn, 2013: Evaluation of the hydrometeor layers in the east and west Pacific within ISCCP cloud-top pressureoptical depth bins using merged CloudSat and CALIPSO data. J. Climate, 26, 9429-9444, doi:10.1175/JCLI-D-12-00207.1.

Morrison, A. E., S. T. Siems, and M. J. Manton, 2011: A three-year climatology of cloud-top phase over the Southern Ocean and North Pacific. J. Climate, 24, 2405-2418, doi:10.1175/ 2010JCLI3842.1.
Oreopoulos, L., and W. B. Rossow, 2011: The cloud radiative effects of International Satellite Cloud Climatology Project weather states. J. Geophys. Res., 116, D12202, doi:10.1029/2010JD015472.

Pincus, R., S. Platnick, G. S. Ackerman, R. J. P. Hofmann, S. A. Ackerman, R. S. Hemler, and R. J. P. Hofmann, 2012: Reconciling simulated and observed views of clouds: MODIS, ISCCP, and the limits of instrument simulators. J. Climate, 25, 4699-4720, doi:10.1175/JCLI-D-11-00267.1.

Protat, A., and Coauthors, 2014: Reconciling ground-based and space-based estimates of the frequency of occurrence and radiative effect of clouds around Darwin, Australia. J. Appl. Meteor. Climatol., 53, 456-478, doi:10.1175/JAMC-D-13-072.1.

Rossow, W., and R. Schiffer, 1999: Advances in understanding clouds from ISCCP. Bull. Amer. Meteor. Soc., 80, 2261-2288, doi:10.1175/1520-0477(1999)080<2261:AIUCFI>2.0.CO;2.

- G. Tselioudis, A. Polak, and C. Jakob, 2005: Tropical climate described as a distribution of weather states indicated by distinct mesoscale cloud property mixtures. Geophys. Res. Lett, 32, L21812, doi:10.1029/2005GL024584.

Stephens, G., and Coauthors, 2008: CloudSat mission: Performance and early science after the first year of operation. J. Geophys. Res., 113, D00A18, doi:10.1029/2008JD009982.

Taylor, K. E., R. J. Stouffer, and G. A. Meehl, 2012: An overview of CMIP5 and the experiment design. Bull. Amer. Meteor. Soc., 93, 485-498, doi:10.1175/BAMS-D-11-00094.1.

Trenberth, K., and J. T. Fasullo, 2010: Simulation of present-day and twenty-first-century energy budgets of the southern oceans. J. Climate, 23, 440-454, doi:10.1175/2009JCLI3152.1.

Verlinden, K. L., D. W. J. Thompson, and G. L. Stephens, 2011: The three-dimensional distribution of clouds over the Southern Hemisphere high latitudes. J. Climate, 24, 5799-5811, doi:10.1175/2011JCLI3922.1.

Webb, M. J., C. Senior, S. Bony, and J. Morcrette, 2001: Combining ERBE and ISCCP data to assess clouds in the Hadley Centre, ECMWF and LMD atmospheric climate models. Climate Dyn., 17, 905-922, doi:10.1007/s003820100157.

Williams, K. D., and G. Tselioudis, 2007: GCM intercomparison of global cloud regimes: Present-day evaluation and climate change response. Climate Dyn., 29, 231-250, doi:10.1007/ s00382-007-0232-2.

- and M. J. Webb, 2009: A quantitative performance assessment of cloud regimes in climate models. Climate Dyn., 33, 141-157, doi:10.1007/s00382-008-0443-1.

_ - and Coauthors, 2013: The Transpose-AMIP II Experiment and its application to the understanding of Southern Ocean cloud biases in climate models. J. Climate, 26, 3258-3274, doi:10.1175/JCLI-D-12-00429.1.

Winker, D. M., W. H. Hunt, and M. J. McGill, 2007: Initial performance assessment of CALIOP. Geophys. Res. Lett., 34, L19803, doi:10.1029/2007GL030135.

Zhang, M. H., 2005: Comparing clouds and their seasonal variations in 10 atmospheric general circulation models with satellite measurements. J. Geophys. Res., 110, D15S02, doi:10.1029/ 2004JD005021. 